\title{
Эпоха бронзы
}

УДК 903

https://doi.org/10.24852/2587-6112.2021.2.6.16

\section{К СТАТИСТИЧЕСКОЙ МЕТОДИКЕ ИЗУЧЕНИЯ КУЛЬТУРНЫХ СЛОЕВ ПОСЕЛЕНИЙ ЭПОХИ БРОНЗЫ (РАБОТА НАД ОШИБКАМИ)}

\author{
(C) 2021 г. И.В. Чечушков
}

В статье предлагается подход к изучению культурного слоя с точки зрения разведочного анализа данных - одного из разделов математической статистики. Культурный слой объекта археологии, зачастую невозможно или нерационально изучить полностью, т. е. подвергнуть полным раскопкам. Поэтому, описываются основные разновидности выборок: случайная выборка, систематизированная случайная выборка и стратифицированная случайная выборка, необходимые для получения неискаженного представления о генеральной совокупности - культурном слое. Также приводятся основные принципы формирования случайных выборок. На примере культурных слоев поселений позднего бронзового века Южного Зауралья описываются статистические методы расчета доверительных интервалов средних и пропорций. Они применяется для изучения насыщенности культурного слоя материальными остатками и их разнообразие для характеристики всей недоступной для изучения генеральной совокупности. В заключение приводится способ расчета необходимой для вскрытия площади для характеристики ранее не изученных объектов. Делается вывод, что в сочетании со статистическим подходом, вскрытие малых площадей может гарантировать изучение культурного слоя при сохранении объекта культурного наследия.

Ключевые слова: археология, разведочный анализ данных в археологии, культурный слой, бронзовый век, поселенческая археология.

\section{STATISTICAL METHODS IN STUDYING OF CULTURAL LAYERS OF THE LATE BRONZE AGE SETTLEMENTS (INCLUDING THE AUTHOR'S CORRECTIONS)}

\section{I.V. Chechushkov}

The paper provides an alternative approach to study of the cultural layers of archaeological sites from the perspective of exploratory data analysis - one of the branches of mathematical statistics. It is often impossible or irrational to perform a complete study of the cultural layer of an archeological site, i. e. to subject it to complete excavations. Therefore, the main types of samples are described: random sampling, systematized random sampling and stratified random sampling, which are required to obtain an undistorted view of the general population - the cultural layer. The basic principles of the formation of random samples are also outlined in the paper. Statistical methods for calculating the confidence intervals of the averages and proportions are described on the example of the cultural layers of the Late Bronze Age settlements of the Southern Trans-Urals. They are used to study the saturation of the cultural layer with material remains and their diversity in order to characterize the entire general population inaccessible for studying. In conclusion, a method is provided for calculating the area required to be excavated in order to characterize the previously unexplored sites. It is concluded that, in combination with a statistical approach, the excavation of small areas can guarantee studying of the cultural layer while preserving the cultural heritage site.

Keywords: archaeology, exploratory data analysis in archaeology; cultural layer; Bronze Age; settlement archaeology

\section{1. Введение}

Насыщенность материальными остатками и их разнообразие - это ключевые характеристики культурного слоя объекта археологии, наиболее значимые при сравнительном анализе. Так, насыщенность культурного слоя поселенческого памятника является ключом к установлению относительной длительности его существования или относительной численности населения. При всех прочих равных, общее количество артефактов или экофактов будет больше для долговременных густонаселенных поселений в сравнении с кратковременными стоянками меньших по численности коллективов (Drennan et al., 2015). Разнообразие категорий находок указывает на основы системы жизнеобеспечения, основные виды деятельности и соци- 
альную организацию. Например, культурные слои специализированных поселков могут характеризоваться меньшим разнообразием, но большим количеством инвентаря конкретных типов, в то время как места жительства основной части населения будут обладать большим количеством категорий и схожими процентными значениями основных категорий (Черных и др., 2002). Таким образом, сравнение характеристик культурных слоев двух или более объектов археологии позволяет объяснить их природу и реконструировать историческую динамику.

Следует оговорится, что общая методика раскопок поселений требует вскрытия больших площадей, поскольку предполагается, что именно такой подход позволяет изучить быт, культуру и другие стороны жизни древнего общества (Авдусин, 1980, с. 107-108). По современным отечественным стандартам вскрытая площадь должна обеспечивать возможность получения полной характеристики памятника, но при этом оставлять возможности для будущих исследований. При этом жилищные впадины и жилые площадки должны исследоваться в границах общего раскопа, охватывающего прилегающее к объекту пространство (Положение..., 2018, c. 19-20). При всей обоснованности данного подхода с точки зрения стремления к получению максимального объема информации о конкретных объектах он имеет свои ограничения, если цель исследования заключается в изучении общей картины прошлого и выявлении закономерностей развития человеческого общества. Это связано с тем, что концентрация на больших площадях и требование полного вскрытия отдельных объектов концентрирует ресурсы и внимание исследователей, ограничивая таким образом формирование представительных выборок для статистического анализа.

Альтернативой принятому методу раскопок большими площадями является подход с точки зрения математической статистики в ее варианте разведочного анализа данных. Его преимущество заключается в возможности выдвигать вероятностные гипотезы для характеристики насыщенности и разнообразия для объекта целиком и сравнивать памятники между собой. Метод предполагает формирование случайных выборок, объективно характеризующих культурный слой (Drennan et al, 2015). Случайная выборка - это такая выборка, где каждому элементу в совокупности дается равный шанс попасть в неё
(Федоров-Давыдов, 1987, с. 15). С точки зрения математической статистики именно случайная выборка лишена искажений, предвзятости выбора (Drennan 2009, с. 85). Закономерности, наблюдаемые в выборке, переносятся на генеральную совокупность (Ковалевская, 1965, с. 287).

Целью данной работы является описание методики формирования и анализа случайной выборки для характеристики насыщенности и разнообразия материалов в культурных слоях поселений бронзового века. Сравнение поселенческих памятников друг с другом по единым основаниям направлено на характеристику образа жизни населения определенной территории в выбранный период времени, а также на сравнение различных памятников и территорий. В качестве примера использованы ранее опубликованные данные по поселению Каменный Амбар (Чечушков и др., 2018), a также выборка неукрепленных поселений позднего бронзового века Южного Зауралья (Алаева, 2017).

\section{2. Методы}

Изучение объекта археологии методами разведочного анализа данных предполагает формирование случайной пространственной выборки путем наложения на изучаемую территорию сети равновеликих участков. Затем из такой сетки случайным образом выбираются участки для проведения исследований. Одной из разновидностей является систематизированная случайная выборка. При такой выборке сеть участков разбивается на сектора равной площади, а затем в пределах каждого из них случайным образом определяется часть для изучения (Drennan, 2009, с. 241-243). Такая стратегия позволяет охарактеризовать достаточно большую территорию, при этом получая наименее искаженную картин. Разумеется, всегда есть шанс, что выбранный случайным образом участок будет наименее репрезентативен с точки зрения определения среднего значения для сектора, однако в теории это компенсируется значениями других секторов. В реальной жизни всегда остается место неудаче. Еще одной разновидностью является стратифицированная случайная выборка, в которой элементы генеральной выборки делятся на группы (Пыслаpy, 2018, с. 196).

Полученные таким методом данные затем могут быть обобщены статистическими методами для характеристики всей площади изучаемого объекта археологии. Числовыми параметрами служат: 1) количественные 
характеристики (среднее и среднеквадратическое отклонение) и 2) пропорции различных категорий материала.

2.1. Метод определения насыщенности культурного слоя

Насыщенность культурного слоя материалами может быть выражена в виде среднего количества находок на единицу площади («шт/ $\left.\mathrm{M}^{2} »\right)$. Первым шагом анализа рассчитывается среднее значение насыщенности по всем выбранным участкам. При условии, что выборка сформирована случайным образом, именно рассчитанное среднее значение будет наиболее близко к истинной характеристике культурного слоя. Далее для оценки степени вариативности выборки следует по формуле (1) рассчитать среднеквадратическое отклонение: чем меньше его значение, тем меньше разница между изученными единицами площади. Однако основная функция среднеквадратического отклонения заключается в том, чтобы на его основе по формуле (2) рассчитать стандартную ошибку среднего - меру, характеризующую интервал нахождения среднего значения изучаемой генеральной совокупности - культурного слоя объекта археологии (Drennan, 2009, с. 29-31, 104-106).

Для расчета среднеквадратического отклонения для малых выборок используется формула:

$$
\begin{aligned}
& \sigma=\sqrt{\frac{\sum(x-\tilde{z})^{2}}{n-1}}(1), \\
& \text { где: }
\end{aligned}
$$

$\sigma$ - среднеквадратическое отклонение выборки,

$x$ - измеренное значение,

$\bar{X}$ - среднее значение выборки,

$n$ - размер выборки (количество изученных раскопом участков).

Для расчета стандартной ошибки (или квадратической ошибки среднего по (Ковалевская, 1965, с. 293)) используется формула:

$S E=\frac{\sigma}{\sqrt{n}} \times t$

где:

$S E$ - стандартная ошибка

$\sigma$ - среднеквадратическое отклонение выборки,

$n$ - размер выборки (количество изученных раскопом участков),

$t$ - значение из таблицы Стьюдента для желаемого уровня доверия при степени свободы $n-1$.
Стандартная ошибка среднего при выбранном доверительном интервале (как правило, это $80 \%, 95 \%$ и 99\%) позволяет охарактеризовать генеральную совокупность, из которой сделана случайная выборка. Полученное значение выражается в виде $\bar{X} \pm S E$, где $\bar{X}-$ среднее арифметическое, а $S E$ - доверительный интервал при желаемом уровне значимости.

2.2. Метод определения разнообразия материального комплекса

Разнообразие материального комплекса может быть охарактеризовано через сопоставление пропорций различных типов артефактов с расчетом стандартных ошибок выявленных пропорций. Как и в первом случае, метод служит для установления интервалов, в которых лежат истинные значения пропорций в генеральной совокупности (при условии, что получена случайная выборка). Для расчета доверительного интервала пропорций используются формулы среднеквадратического отклонения пропорции (3) и стандартной ошибки пропорции (4) (Федоров-Давыдов, 1987, c. 48-51; Drennan, 2009, c. 139-142):

$$
\begin{aligned}
& \sigma=\sqrt{p q} \\
& \text { где: }
\end{aligned}
$$

$\sigma$ - среднеквадратическое отклонение пропорции,

$p$ - пропорция, выраженная в десятичной форме,

$$
\begin{aligned}
& q=1-p ; \\
& S E=\frac{\sigma}{\sqrt{n}} \times t
\end{aligned}
$$

где:

$S E$ - стандартная ошибка пропорции,

$\sigma$ - среднеквадратическое отклонение пропорции,

$n$ - общий размер выборки, из которой происходит пропорция,

$t$ - значение из таблицы Стьюдента для желаемого уровня доверия при 120 степенях свободы.

Стандартная ошибка для пропорции позволяет оценить истинное значение доли того или иного типа в генеральной совокупности, а также демонстрирует, достаточно ли велика выборка для такой оценки. Чем меньше изучаемая выборка, тем больше будут пересекаться интервалы ошибок пропорций, сигнализируя, что еe размер может быть слишком мал для суждений о популяции (Ковалевская, 1965, с. 287). 
3. Материалы и анализ

3.1. Сравнительный анализ насыщенности культурного слоя

Описываемая статистическая методика была использована при изучении культурного слоя поселения Каменный Амбар в Карталинском районе Челябинской области. Поселение относится к категории городищ, где основная жилая часть обнесена насыпной стеной и окружным рвом. Площадка памятника в пределах стены составляет 16000-18000 м². Эта территория изучалась комплексной археологической экспедицией с применением методов геофизики, геохимии, а также раскопов большими площадями. Для наиболее полной характеристики внутренней структуры и стратиграфии памятника раскопы были заложены в четырех разных частях памятника, восемью участками, часть из которых была смежной, с учетом рельефа руинизированных сооружений и выявленных магнитных аномалий. В процессе вскрытия культурного слоя велся просев грунта с регистрацией всего культурного материала. Изученная раскопками площадь составила 1888 м², или 10,4\% от общей площади памятника (Корякова и др., 2011; Krause and Koryakova, 2013) ${ }^{1}$. Полученная коллекция находок может быть определена как систематизированная случайная выборка размером около $10 \%$, характеризующая всю генеральную совокупность артефактов и экофактов в культурном слое поселения.

С целью выявления и изучения культурного слоя за пределами окружной стены автором было проведено разведочное исследование прилегающей территории (рис. 1). Площадь для изучения была определена исходя из гипотезы, что культурный слой простирается на 100 м от видимых границ городища. Поэтому от воображаемого прямоугольника границ памятника была разбита сетка, отступающая на 100 м в три стороны, покрывая общую

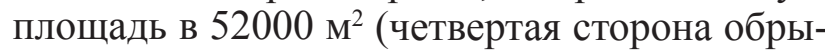
вается в реку Карагайлы-Аят, поэтому из работы была исключена). Комплексная полевая методика включала бурение с регистрацией стратиграфии, находок и отбором почвенных образцов на химический анализ, зачистку стенок оврагов для описания почвенной ситуации, а также шурфовку методом систематизированной случайной выборки (Чечушков и др., 2018a, 2018b). Всего было выполнено 130 бурений, сделано 10 зачисток и заложено 17 разведочных шурфов, грунт которых просеивался в ходе разбора. Общая вскрытая

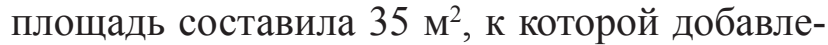

ны материалы из пяти шурфов других исследователей, т. е. общая площадь составляет 40 $\mathrm{M}^{2}$. В относительном выражении раскопками была изучена лишь незначительная доля в $0,07 \%$ от общей площади в пределах сетки. При этом места закладки шурфов во многом концентрировались вокруг магнитных аномалий, снижая степень случайности выборки. С учетом того, что выявленная в результате исследования общая площадь культурно-

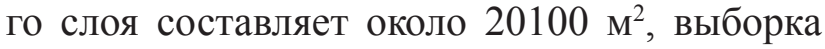
составила $0,2 \%{ }^{2}$.

Полученные выборки могут быть определены как систематизированные случайные и сравнены для характеристики культурных слоев внутри и снаружи обводной стены поселения. Далее описывается методика и некоторые результаты такого сравнения.

Для расчета среднего значения насыщенности и его доверительных интервалов для культурного слоя внутри окружной стены применен подход стратифицированной выборки. Другими словами, поскольку отчетные материалы и публикации не приводят данных о количестве материалов индивидуально для каждого квадратного метра площади, расчет производится как среднее значение для всех раскопов. Размер стратифицированной выборки определяется количеством раскопов и равен восьми $(n=8)$, что соответствует семи степеням свободы по таблице Стьюдента. Чем меньше степеней свободы, тем больше значение $t$ (количество стандартных ошибок под кривой нормального распределении) и тем шире доверительный интервал. Соответственно, хотя стратифицированная выборка и меньше по размеру, чем возможная оригинальная (ее размер равняется числу вскрытых квадратных метров, $n=1888)$, даже она дает возможности оценки. Произведя расчет описываемым методом, получаем, что общая насыщенность находками внутри стен поселения составляет 8,2 $\pm 3,9$ артефакта на 1 м $^{2}$ (95\% доверительный интервал, далее - ДИ; $n$ $=8 ; \sigma=4,7)$. Небольшое значение среднеквадратического отклонения $(\sigma=4,7)$ говорит о несущественной вариативности насыщенности находками и достаточно равномерном их распределении по площади.

Для расчета среднего значения плотности материала в культурном слое за пределами стен поселения также используется стратифицированная выборка, размер которой $n=22$. Это связано с тем, что некоторые из шурфов были площадью $2 \mathrm{~m}^{2}$ или $4 \mathrm{~m}^{2}$, а находки фиксировались для всей площади шурфа. В 


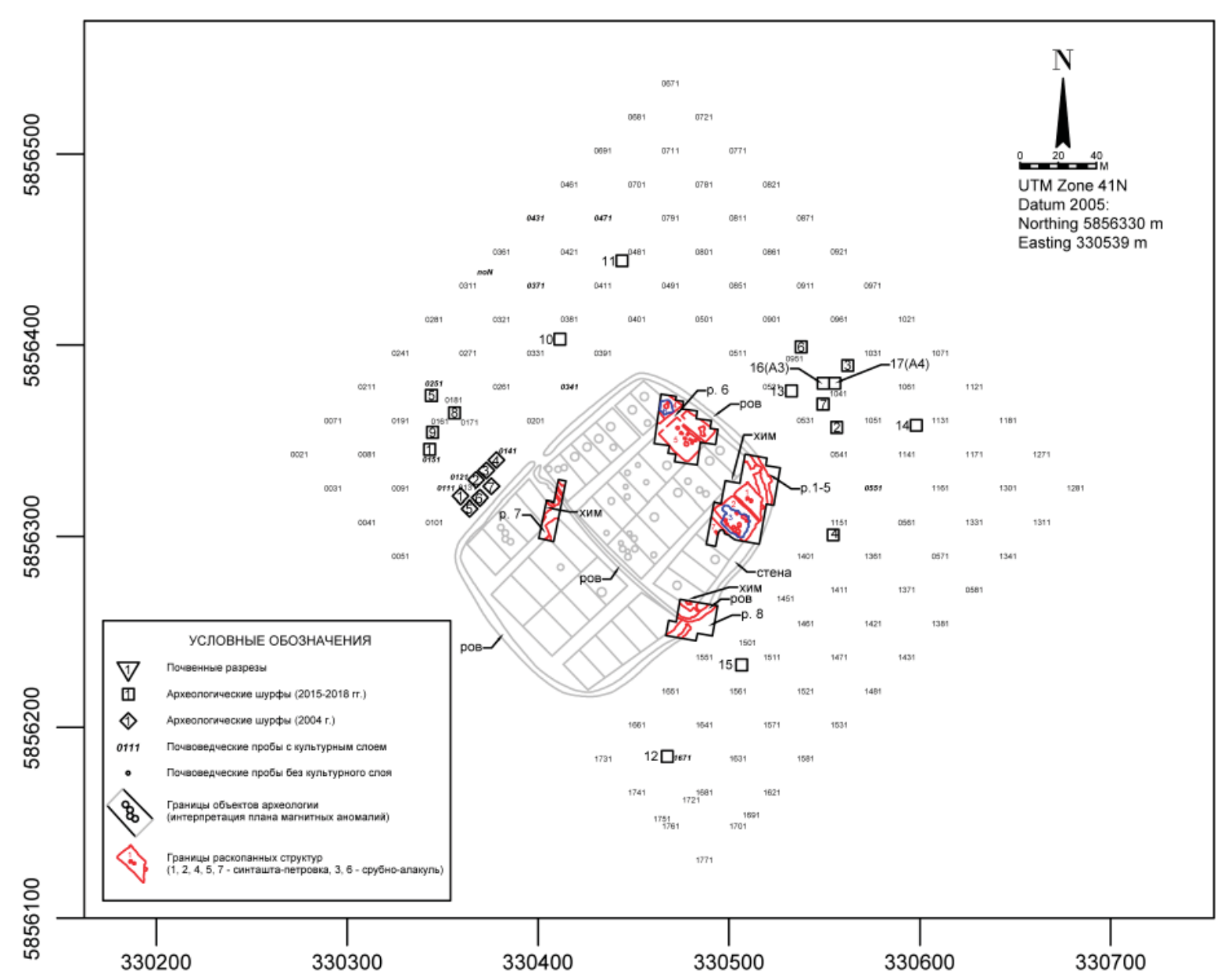

Рис 1. Поселение Каменный Амбар: структура памятника по данным магнитометрии, места расположения раскопок и зона археологической разведки в прилегающей округе

Fig 1. The settlement of Kamennyi Ambar: the site's structure in accordance with the magnetometry, the location of excavated areas and the survey zone outside the border

соответствии с данными шурфовки, средняя насыщенность слоя составляет 12,4 $\pm 5,4$ артефактов на $1 \mathrm{~m}^{2}(95 \%$ ДИ; $n=22 ; \sigma=10,4)$. Большое значение среднеквадратического отклонения, близкое среднему $(\sigma=10,4)$, указывает на существенную вариативность выборки, значения которой варьируют от 1,5

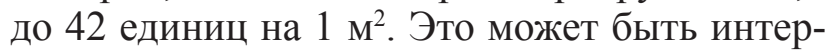
претировано как чрезвычайно неоднородная насыщенность культурного слоя с областями большой концентрации и почти свободными от материала.

Сравнение показывает схожие средние значения насыщенности культурного слоя внутри и за пределами стены городища при чуть более высоком показателе снаружи $(8,2: 12,4)$. Однако статистический подход позволяет проверить это заключение. Так, доверительные интервалы ошибок средних при 95\% пересекаются, указывая что истинная ситуация может быть обратной наблюдаемой: насыщенность материалом внутри выше, чем снаружи. Таким образом, требуется дополнительная проверка для уточнения как средних, так и их стандартных ошибок. Для материалов из раскопов внутри стен это возможно сделать путем дальнейшей работы с полевыми описями и увеличением размера выборки путем определения плотности материалов на каждом участке. Для уточнения значений насыщенности снаружи требуется увеличение выборки шурфов при большем их распределении по площади.

Учитывая тот факт, что керамика составляет основу коллекции в каждом случае (95\% внутри и $87 \%$ снаружи), далее следует сравнить насыщенность именно этой категорией. Средняя насыщенность керамикой в пределах жилищ составляет $7,8 \pm 3,8$ шт/м $\mathrm{M}^{2}$ (при 95\% ДИ), а за пределами стен она составляет $11 \pm 4,1$ шт/м ${ }^{2}$. Статистически средние значения плотности керамики достаточно близки, и двухсторонний $t$-тест не опровергает нулевую гипотезу о равенстве средних $(t=0,9$, $p=0,35)$.

Однако важно то, что керамический материал имеет очевидную тенденцию к неоднородной фрагментации, поэтому подсчет 
количества найденных фрагментов неинформативен с точки зрения определения насыщенности: один и тот же сосуд может быть представлен разным количеством фрагментов в зависимости от условий тафономизации. Гораздо более информативен подсчет веса на единицу площади, поскольку это дает более точную картину насыщенности даже с учетом разной толщины стенок сосудов (последнее может быть скорректировано расчетом среднего веса фрагмента и стандартной ошибки).

Так, анализ показал, что средний вес фрагментов из шурфов составляет 2,6 $\pm 0,3$ г (10\% усеченное среднее при 95\% ДИ, $n=603)$. В то же время случайная выборка $(n=50)$ фрагментов в пределах стен продемонстрировала значение $25,1 \pm 7,5$ г (10\% усеченное среднее при 95\% ДИ). Наблюдаемая разница сильна и значительна $(t=5,97, \mathrm{p}<0,005)$. Данное сравнение показывает, что, несмотря на схожие количественные показатели, качественно две выборки существенно отличаются друг от друга: фрагментированность керамики снаружи значительно выше, чем внутри. Однако это сравнение не может считаться достоверным, т. к. выборка керамики из раскопов внутри стены была преднамеренно искажена исследователями. Дело в том, что фрагменты размером менее $2 \times 2$ см попадали в так называемую категорию «выброс», были подсчитаны и в соответствии с п. 4.33 действующего «Положения...» оставлены на месте полевых работ. Другими словами, информация о весе и размере фрагментов была утрачена. Поэтому среднее значение веса, рассчитанное для целей настоящей работы, также является искаженным. Единственным доступным способом сравнения является внесение аналогичного искажения в выборку керамики снаружи, удалив все фрагменты размером менее $2 \times 2$ см $(n=294)$. В результате усеченное среднее составит 5,4 $\pm 0,5$ г, что по-прежнему существенно ниже среднего веса фрагментов из жилищ. Однако учитывая, что в категории «выброс» попало 52\% всех найденных фрагментов (6932/13297), уверенности в адекватности сравнения быть не может. Единственное доступное заключение в том, что в выборке внутри стен значительное число фрагментов в среднем крупнее, чем снаружи.

Помня о существующем искажении, все же можно произвести умножение средней плотности керамики на её средний вес. Это позволяет сравнить две области через пока-

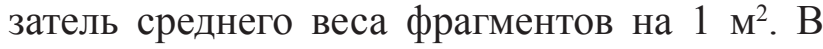
результате в жилищах поселения средний вес составляет $195,7 \pm 28,5$ г/M², а за пределами стен средний вес преднамеренно искаженной выборки (без «выброса») составляет 59 $\pm 2,2$ г/M². Несмотря на указанное искажение выборки, расчёты демонстрируют качественные различия между двумя сравниваемыми совокупностями. В целом меньший средний вес керамических материалов в культурном слое за стенами означает их меньшее количество - керамические материалы, оставленные в древности, получили схожие количественные значения в процессе тафомизации, но их общая масса изначально была ниже.

Схожую проблему сравнения культурных слоев по степени насыщенности керамическим материалом поставила И.П. Алаева (2017). Автор провела сравнение культурных слоев 16 неукрепленных поселений позднего бронзового века Южного Урала с целью изучения проблемы долговременности существования поселений и одновременности их функционирования. Исследование выявило существенную разницу в насыщенности слоя между степной и лесостепной группами памятников: поселения степной зоны $(n=12)$ имели насыщенность в 2-5 фрагментов керамики на $1 \mathrm{M}^{2}$, а лесостепные $(n=4)$ - 15-17 фрагментов на $1 \mathrm{~m}^{2}$. Произведя простой подсчет, автор заключает, что поселения первой группы были менее долговременными по сравнению с синхронными поселениями второй группы, что может объясняться различной емкостью двух экологических ниш.

Возможной проблемой данного анализа является искаженность выборок. Так, методики раскопок и сбора материала могут существенно отличаться от памятника к памятнику, внося искажения по неизвестным основаниям. Как было показано выше, степень раздробленности керамики может быть различной, поэтому количественные показатели не всегда являются адекватными единицами сравнения. Тем не менее статистически возможно провести проверку полученных результатов. Предположим, что внесенные искажения существенно повлияли на выборку керамики в каждом из памятников. Значит, не будет наблюдаться никакой закономерности между общей раскопанной площадью и общим количеством собранной авторами раскопок керамики. Для проверки этой гипотезы сначала рассмотрим всю выборку с помощью гистограммы «ствол и листья». Она демонстрирует приближенное к нормальному распределение со шлейфом справа и далеким выбросом (30000), который может быть устранен из анализа (рис. 2). 


\begin{tabular}{|c|c|}
\hline \multirow{5}{*}{$\begin{array}{l}\text { Minimum: } 540 \\
\text { Lower Hinge: } 1950 \\
\text { Median: } 2996,5 \\
\text { Upper Hinge: } 7351 \\
\text { Maximum: } 30000\end{array}$} & \\
\hline & Рис. 2. Диаграмма «ствол \\
\hline & \\
\hline & насыщенности керамическим \\
\hline & материалом культурных слоев \\
\hline $\begin{array}{ll}0 & 0011 \\
0 & 2222333\end{array}$ & позднего бронзового века \\
\hline $\begin{array}{ll}0 & 2222333 \\
0 & \end{array}$ & Южного Урала (данные по: \\
\hline $\begin{array}{ll}0 & 6 \\
0 & 89\end{array}$ & [Алаева, 2017]). \\
\hline
\end{tabular}

Fig 2. The steam and leaf plot showing the distribution ceramic densities in Late Bronze Age archaeological sites in the Southern Urals (after [Alaeva, 2017])

30

Для анализа регрессии раскопанная площадь может быть принята как независимая переменная, а общее количество керамики как зависимая. Регрессия показала сильную положительную связь между переменными $(r=0,77, p=0,0008)$, которая объясняет 59\% вариаций $\left(r^{2}=0,59\right)$. Другими словами, даже с искажением по неизвестным основаниям закономерность в насыщенности керамикой культурных слоев все же есть, поскольку $59 \%$ вариативности объяснено выявленной корреляцией. Для дальнейшего сравнения двух природных зон требуется увеличение лесостепной выборки поселений, поскольку ее размер слишком мал для статистических методов. Увеличение выборки может быть осуществлено описанным выше случайным методом без раскопок больших площадей.

3.2. Сравнительный анализ разнообразия материального комплекса

Примером изучения разнообразия артефактов может служить анализ категорий находок из шести жилищ поселения Каменный Амбар и культурного слоя за стеной. Для целей анализа все находки на основании типологического и трасологического анализов могут быть объединены в восемь основных групп: 1) косторезные инструменты; 2) инструменты керамического производства; 3) украшения; 4) домашняя утварь; 5) орудия кожевенного производства; 6) орудия металлопроизводства и свидетельства металлургического производства; 7) орудия текстильного производства; 8) оружие, колесничный комплекс и символы статуса. Фрагменты керамических сосудов из выборки исключаются как наиболее многочисленная категория. Затем производится подсчет количества предметов в каждой группе для каждого жилища и стандартный подсчет долей каждой из категорий.

Далее производится расчет стандартной ошибки для каждой пропорции, позволяю- щий оценить степень гомогенности каждой из выборок. Наиболее гомогенная будет иметь малое количество категорий и большую пропорцию одной из них, а наиболее гетерогенная - большее количество категорий и близкие значения долей. Кроме того, доверительные интервалы позволяют сформировать вероятностное представление о том, каким могло быть истинное соотношение категорий артефактов в древности. Так, пересекающиеся интервалы будут свидетельствовать, что нельзя быть уверенным в том, что археологизированная выборка адекватно отражает прошлую реальность.

Анализ выборки артефактов Каменного Амбара (рис. 2А) демонстрирует следующее. Во-первых, четыре выборки из шести имеют достаточный размер для демонстрации разницы между некоторыми категориями артефактов (постройки 1, 2, 4 и 5). С другой стороны, для построек 3 и 6 выборки слишком малы для обоснованных заключений. Во-вторых, анализ показывает, что между жилищами также существует разница в композиции артефактов, что, возможно, свидетельствует о производственной специализации между семьями или разнице в степени богатства. Так, постройка 1 выделяется существенно большей пропорцией инструментов керамического производства в сравнении с другими помещениями, а доверительные интервалы этой категории в постройке 1 не пересекаются с аналогичными в других. В-третьих, во всех случаях в выборках превалируют свидетельства металлургического производства, включая культурный слой снаружи.

Последнее обстоятельство наводит на заключение, что свидетельства металлургического производства искажают картину за счет избыточности в ней шлака. Исключение этой категории из анализа (рис. 2В) позволяет масштабировать результирующий график (ведь остальные пропорции не поменялись относительно друг друга) и заключить, что постройка 1 выделяется наибольшей гомогенностью артефактного комплекса. Это наблюдение может свидетельствовать о характере использования данной постройки, которая, например, могла быть хозяйственной, а не жилой.

\section{4. Обсуждение результатов}

Проведенный анализ демонстрирует преимущества статистического подхода, позволяющего формулировать гипотезы об изучаемой совокупности на основании выборочных данных. Кроме того, он показывает ограни- 


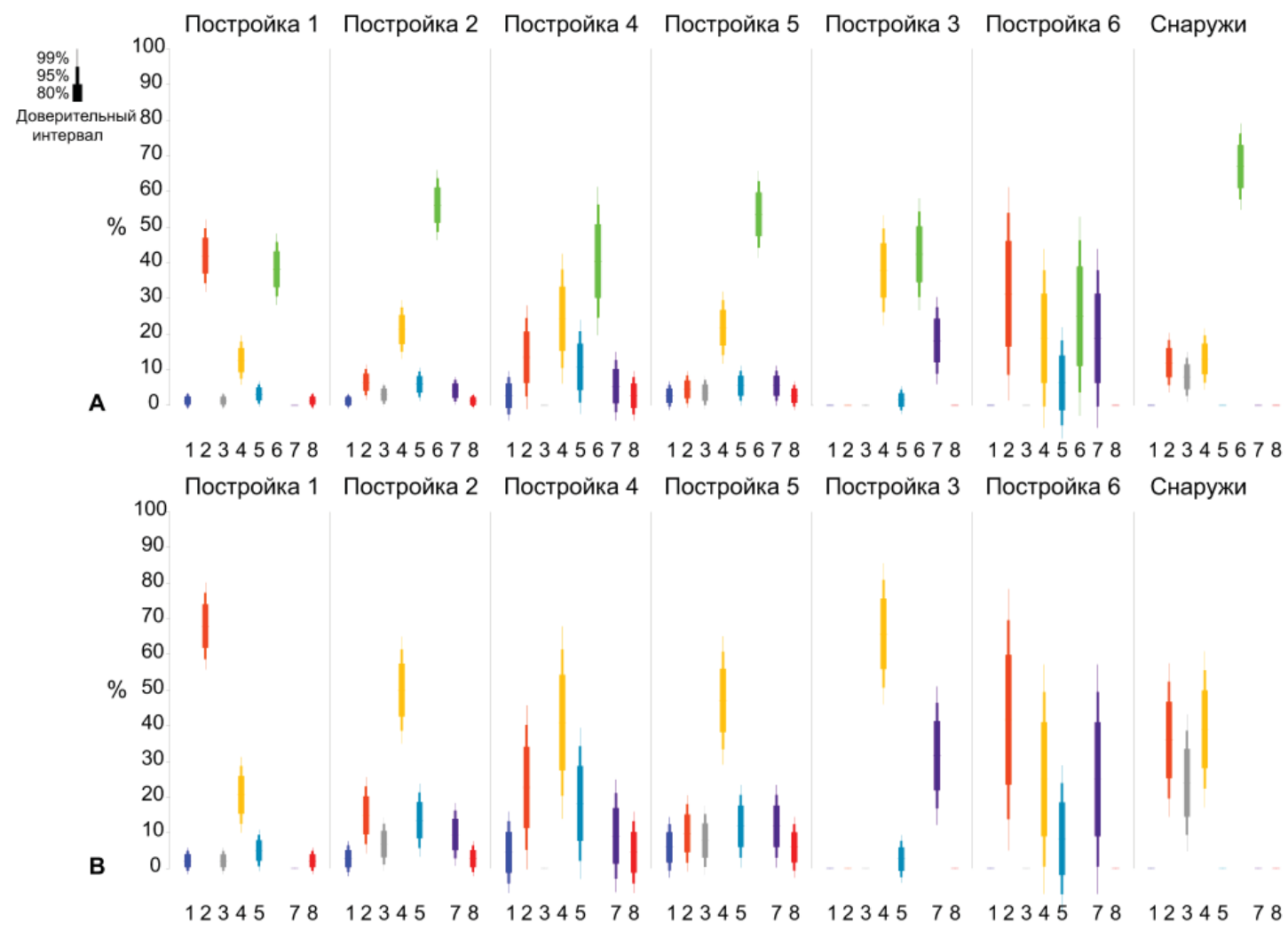

Рис 3. Пропорции типов артефактов в культурном слое поселения Каменный Амбар: А - все типы; В пропорции без учета артефактов металлопроизводства. 1) косторезные инструменты; 2) инструменты керамического производства; 3) украшения; 4) домашняя утварь; 5) орудия кожевенного производства; 6) орудия металлопроизводства и свидетельства металлургического производства; 7) орудия текстильного производства;

8) оружие, колесничный комплекс и символы статуса.

Fig 3. Proportions of artifacts of principal categories in the cultural layer of Kamennyi Ambar: A - all types; B - proportions excluding artifacts associated with metal production. 1 - bone-working tools; 2 - ceramic production tools; 3 -decoration; 4 - household items; 5 - leather-working tools; 6 - metallurgy production; 7 - textile production tools; 8 - weapons, chariot complex and status items.

чения традиционного подхода и некоторые ошибки, связанные с ориентацией исследователей на принятые в отечественной археологии нормы. Так, например, выборка шурфов в округе Каменного Амбара не может быть признана строго случайной, поскольку при их закладке автор в том числе ориентировался на карту магнитных аномалий и стремился уточнить их природу шурфовкой. Это привело к внесению в выборку искажений по известным основаниям.

При дальнейшем исследовании культурного слоя за стенами Каменного Амбара, как и в любых других случаях, следует исходить из правил формирования случайной систематизированной выборки, одним из вариантов которой может быть работа в сетке. Эффективность такого подхода продемонстрирована при исследовании системы расселения в долине р. Зингейки (Sharapov, 2020).

Кроме того, регистрация находок по шурфам, а не по квадратным метрам привела к искусственному сокращению размера выборки с 40 до 22. В этой связи имеет смысл отказаться от вскрытия шурфов площадью больше чем $1 \mathrm{M}^{2}$. При характеристике культурных слоев других поселений в будущем необходимое количество шурфов площадью $1 \mathrm{~m}^{2}$ может быть определено математически исходя из данных шурфовки в округе Каменного Амбара. Для определения насыщенности культурного слоя может быть использована следующая формула (Drennan, 2009, с. 126-127):

$$
\begin{aligned}
& n=\left(\frac{\sigma t}{E R}\right)^{2}(5), \\
& \text { где: } \\
& n-\text { размер выборки; } \\
& \sigma \quad-\text { среднеквадратическое отклонение }
\end{aligned}
$$
выборки из культурного слоя в округе Каменного Амбара, равное 10,4;

$t$ - количество стандартных ошибок по таблице Стьюдента для желаемого уровня доверия и бесконечного количества степеней свободы;

$E R$ - желаемый доверительный интервал в измеряемых единицах (например, 5,4 единицы для 95\% ДИ на Каменном Амбаре). 
Решая задачу определения размера выборки по формуле (5), приходим к заключению, что для желаемого уровня точности в $\pm 5,4$ единицы при ДИ в 95\% $(t=1,96)$, необходимо вскрыть 14 или 15 шурфов. Учитывая, что действующее Положение позволяет вскрывать до $20 \mathrm{~m}^{2}$ на одном объекте культурного наследия в пределах действия одного Открытого листа, точность определения может быть повышена до $\pm 4,5$ единиц при 95\% ДИ. Также важно отметить, что стандарты классической статистики части определяют минимальнонеобходимый размер выборки в 5\% от размера популяции. Для культурного слоя площадью 20100 м $^{2}$ у стены Каменного Амбара это значение составит $1005 \mathrm{~m}^{2}$, что входит в противоречие с действующим законодательством, регулирующим археологические разведки. Тем не менее стандарт 5\% не является обязательным для разведочного анализа данных, примененного в настоящей работе (Drennan, 2009, c. 127).

\section{5. Заключение}

На примере анализа материалов памятников позднего бронзового века были продемонстрированы методы определения насыщенности культурного слоя методом случайной выборки без вскрытия значительных площадей. На поселении Каменный Амбар это позволило заключить, что культурный слой за пределами стен городища насыщен значительно меньше, а материал фрагментирован сильнее, чем внутри. Это поставило вопрос о природе обнаруженного культурного слоя и его социально-исторической интерпретации.
В другой работе (Чечушков и др. 2018) было высказано предположение, что данный культурный слой был сформирован в процессе обживания прилегающей территории мобильными группами населения. Также была проверена гипотеза о том, что разная степень насыщенности культурных слоев неукрепленных поселений в степном и лесостепном Зауралье может быть связана с разным временем их существования. Несмотря на то, что степень искажения выборок остается неизвестной, выявленная закономерность не опровергает версию И.П. Алаевой о меньшем времени функционирования степных памятников.

Кроме того, была продемонстрирована методика анализа пропорций различных категорий инвентаря. Показано, что, несмотря на различные значения в выборках, истинные доли могли отличаться от выявленных в ходе раскопок.

Описанная здесь статистическая методика изучения поселенческих памятников хорошо согласуется с современной ориентацией на минимизацию ущерба от раскопок и все более широкого применения междисциплинарного подхода. Так, задача картографирования, изучения внутренней структуры и характеристики хозяйственной деятельности археологии успешно решается неразрушающими или малоинвазивными методами геостатистики (Чечушков, 2015), геофизики (Носкевич, Федорова, 2010; Федорова, Носкевич, 2012 и др.) и геохимии (Бикмуллина, 2017; Krause and Koryakova, 2013).

\section{Примечания:}

${ }^{1}$ С учетом раскопа 1992 года общая вскрытая площадь составляет около 2320 м², но отсутствие просева и индивидуальной фиксации не позволяет использовать его данные для статистического анализа.

${ }^{2}$ В статье 2018 г. (Чечушков и др., 2018), на с. 154 вкралась опечатка - «49 м²» следует читать как «39 м²», и тоже самое на рис. 5С. Также, опечатка на с. $156: « 8,8 \pm 3,9 »$ следует читать «8,2 $\pm 3,9 »$ и тоже на рис. 5С. На с. 157 следует читать: «двухсторонний t-тест не опровергает нулевую гипотезу $(t=0,01, p=0,99) »$.

\section{ЛИТЕРАТУРА}

Авдусин Д.А. Полевая археология СССР. М., 1980. 335 с.

Алаева И.П. Проблема продолжительности существования поселений бронзового века Южного Зауралья // V (XXI) Всероссийский археологический съезд. Сборник научных трудов [Электронный ресурс] / Отв. ред. А.П. Деревянко, А.А. Тишкин. Барнаул: Изд-во АлтГУ, 2017. С. 51-52.

Бикмулина Л.Р., Якимов А.С., Куприянова Е.В., Чечушков И.В., Баженов А.И. Геохимические особенности «зольника» поселения бронзового века Стрелецкое-1 лесостепного Зауралья. // Вестник археологии, антропологии и этнографии. 2017. № 4(39). С. 154-163.

Ковалевская (Деопик) В.Б. Применение статистических методов к изучению массового археологического материала // Археология и естественные науки / Под ред. Б. А. Колчина. М.: Наука, 1965. C. 286-301.

Корякова Л.Н., Краузе Р., Епимахов А.В., Шарапова С.В., Пантелеева С.Е., Берсенева Н.А., Форнасъе Й., Кайзер Э., Молчанов И.В., Чечушков И.В. Археологические исследования укрепленного поселения Каменный Амбар (Ольгино) // Археология, этнография и антропология Евразии. 2011. № 4(48). C. 64-74. 
Носкевич В.В., Федорова Н.В., Муравьев Л.А. Картирование археологических памятников с помощью магнитометрии // Уральский геофизический вестник. 2010. № 2(17). С. 47-52.

Положение о порядке проведения археологических полевых работ и составления научной отчетной документации (Утверждено постановлением Отделения историко-филологических наук Российской академии наук от 20 июня 2018 г. № 32 // https://www.archaeolog.ru/media/OPI/Polozhenie_2018_2.pdf (дата обращения: 17.03.2021).

Пьсслару И. Роль выборки для статистической обработки археологических материалов // Фундаментальные и прикладные исследования: от теории к практике. Материалы II Международной научнопрактической конференции, приуроченной ко Дню Российской науки. Воронеж: ООО "АМиСта", 2018. C. 194-201.

Федоров-Давыдов Г.А. Статистические методы в археологии: Учебное пособие для вузов по спец. «История». М.: Высшая школа, 1987. 216 с.

Федорова Н.В., Носкевич В.В. Реконструкция планировки укрепленных поселений эпохи бронзы на Южном Урале (Ольгино и Коноплянка) по результатам детальной магнитной съемки // Уральский геофизический вестник. 2012. № 1(19). С. 52-59.

Черных Е.Н., Лебедева Е.Ю., Журбин И.В., Лопес-Саеи Х. А., Лопес-Гарсия П., Мартинес-Наваррете М.И.Н. Каргалы.: Горный - поселение эпохи поздней бронзы: Топография, литология, стратиграфия: Производственно-бытовые и сакральные сооружения: Относительная и абсолютная хронология / Каргалы. Т. II / Ред. и сост. Е. Н. Черных. М.: Языки славянской культуры, 2002. 184 с.

Чечушков И.В. Методы геостатистики в изучении поселенческих памятников бронзового века // Этнические взаимодействия на Южном Урале: материалы VI Всероссийской научной конференции (г. Челябинск, 28 сентября - 2 октября 2015 г.) / Ред. А.Д. Таиров. Челябинск: Челябинский государственный краеведческий музей, 2015. С. 90-96.

Чечушков И.В., Якимов А.С., Бачура О.П., Ын Я.Ч., Гончарова Е.Н. Общественное устройство синташтинско-петровских коллективов позднего бронзового века и причины генезиса социальной элиты (на примере поселения Каменный Амбар в степном Зауралье) // Stratum plus. 2018a. № 2. C. 149-166.

Чечушков И.В., Якимов А.С., Гончарова Е.Н., Молчанова В.В. Определения химических характеристик, границ распространения и общей площади культурного слоя на поселении эпохи бронзы Каменный Амбар в Южном Зауралье // Археология и естественные науки в изучении культурного слоя объектов археологического наследия. Материалы междисциплинарной научной конференции. Москва, 14-15 ноября 2018 г. / Под ред. Д.С. Коробова, А.В. Борисова, С.Н. Удальцова. М.: КМК, 2018b. С. 197-204.

Drennan R.D. Statistics for archaeologists. A commonsense approach. Interdisciplinary contributions to archaeology: Springer, 2009. Interdisciplinary contributions to archaeology. 237 p.

Drennan R.D., Berrey C.A., Peterson C E. Regional settlement demography in archaeology. Clinton Corners, New York: Eliot Werner Publications, Incorporated, 2015.

Krause R., Koryakova L.N. Multidisciplinary Investigations of the Bronze Age Settlements in the Southern Trans-Urals (Russia). Habelt, 2013.

Sharapov D.V. Recent methodological approaches to regional settlement pattern survey in the Eurasian steppes // Archaeological Research in Asia. 2020. Vol. 21. P. 100-173

Информация об авторе:

Чечушков Игорь Владимирович, кандидат исторических наук, старший научный сотрудник, Институт истории и археологии УрО РАН (г. Екатеринбург, Россия); chivpost@gmail.com

\section{REFERENCES}

Avdusin, D. A. 1980. Polevaia arkheologiia SSSR (Field Archaeology of USSR). Moscow: "Vysshaia shkola" Publ. (in Russian).

Alaeva, I. P. 2017. In Derevyanko, A. P., Tishkin, A. A. (eds.). V (XXI) Vserossiyskiy arkheologicheskiy $s^{\prime \prime} e z d$. Sbornik nauchnykh trudov [Elektronniy resurs] (V (XXI) All-Russian Archaeological Congress [Electronic Resource]). Barnaul: Altai State University, 51-52 (in Russian).

Bikmullina, L. R., Yakimov, A. S., Kupriyanova, E. B., Checheshkov, I. V., Bazhenov, A. I. 2017. In Vestnik arkheologii, antropologii i etnografii (Bulletin of Archaeology, Anthropology and Ethnography) 39 (4), 154-163 (in Russian).

Kovalevskaya (Deopik), V. B. 1965. In Kolchin, B. A. (ed.). Arkheologiia i estestvennye nauki (Archaeology and Natural Sciences). Moscow: "Nauka" Publ., 286-301 (in Russian).

Koryakova, L. N., Krauze, R., Epimakhov, A. V., Sharapova, S. V., Panteleeva, S. E., Berseneva, N. A., Fornas'e, I., Kaizer, E.,m Molchanov, I. V., Chechushkov, I. V. 2011. In Arkheologiia, etnografiia i antropologiia Evrazii (Archaeology, Ethnology \& Anthropology of Eurasia) 48 (4), 64-74 (in Russian).

Noskevich, B. V., Fedorova, N. V., Murav'eva, L. A. 2010. In Ural'skii geofizicheskii vestnik (Ural Geophysical Bulletin) 17(2), 47-52 (in Russian). 
Polozhenie o poriadke provedeniia arkheologicheskikh polevykh rabot i sostavleniia nauchnoi otchetnoi dokumentatsii (Utverzhdeno postanovleniem Otdeleniia istoriko-filologicheskikh nauk Rossiiskoi akademii nauk ot 20 iiunia 2018 g. № 32) (Regulations of archaeological fieldworks and scientific reporting (approved through Decision no. 32 of the History and Philology Department of the Russian Academy of Sciences on 20 June 2018)). Available at: https://www.archaeolog.ru/media/OPI/Polozhenie_2018_2.pdf (accessed 17.03.2021) (in Russian).

Pyslaru, I. 2018. In Fundamental'nye i prikladnye issledovaniia: ot teorii k praktike (Fundamental and Applied Studies: from Theory to Practice). Voronezh: “AMiSta” Ltd., 194-201 (in Russian).

Fedorov-Davydov, G. A. 1987. Statisticheskie metody v arkheologii: Uchebnoe posobie dlia vuzov po spets. «Istoriia» (Statistical Methods in Archaeology: Study Guide for Universities with Specialization in History). Moscow: "Vysshaia shkola" Publ. (in Russian).

Fedorova, N. V., Noskevich, V. V. 2012. In Ural'skiy geofizicheskiy vestnik (Ural Geophysical Journal) 1(10), 52-59 (in Russian).

Chernykh, E. N., Lebedeva, E. Yu., Zhurbin, I. V., López- García, P., López-Sáez, J. A., Martínez-Navarrete, M. N. 2002. Kargaly: Gorny - poselenie epokhi pozdnei bronzy. Topografia, litografiia, stratigrafiia. Proizvodstvenno-bytovye i sakral'nye sooruzheniia. Otnositel'naia i absoliutnaia khronologiia (Kargaly: Gorny — the Late Bronze Age Settlement .Topography, lithology, stratigraphy. Household, manufacturing and sacral structures. Relative and absolute chronology). Series: Kargaly 2. Moscow: Moscow: "Iazyki slavianskoi kul'tury" Publ. (in Russian).

Chechushkov, I. V. 2015. In Tairov, A. D. (ed.). Etnicheskie vzaimodeistviia na Iuzhnom Urale: materialy VI Vserossiiskoi nauchnoi konferentsii (g. Cheliabinsk, 28 sentiabria - 2 oktiabria 2015 g.) (Ethnic Interactions in the Southern Urals: Materials of the 6th All-Russian Scientific Conference (Chelyabinsk, September 28th - October 2nd, 2015)). Cheliabinsk: Cheliabinsk Museum of Local Lore, 90-96 (in Russian).

Chechushkov, I. V., Yakimov, A. S., Bachura, O. P., Yn, Ya. Ch., Goncharova, E. N. 2018a. In Stratum plus. Archaeology and Cultural Anthropology (2), 149-166 (in Russian).

Chechushkov, I. V., Yakimov, A. S., Goncharova, E. N., Molchanova, V. V. 2018. In Korobov, D. S., Borisov, A. V., Udal'tsov, S. N. (eds.). Arkheologiya i estestvennye nauki v izuchenii kul'turnogo sloya ob"ektov arkheologicheskogo naslediya (Archaeology and natural Sciences in the study of the cultural layer of archaeological heritage). Moscow: "KMK Scientific Press" Publ., 197-204 (in Russian).

Drennan R. D.2009. Statistics for archaeologists. A commonsense approach. Interdisciplinary contributions to archaeology: Springer, 2009. Interdisciplinary contributions to archaeology. Drennan, R. D., Berrey, C. A., Peterson, C. E. 2015. Regional settlement demography in archaeology. Clinton Corners, New York: Eliot Werner Publications, Incorporated.

Krause, R., Koryakova, L. N. 2013. Multidisciplinary Investigations of the Bronze Age Settlements in the Southern Trans-Urals (Russia). Habelt.

Sharapov, D. V. 2020. In Archaeological Research in Asia. 21, 100-173.

\section{About the Author:}

Chechushkov Igor V. Candidate of Historical Sciences. Institute of History and Archaeology, Ural branch of the Russian Academy of Sciences. S. Kovalevskoy, Str., 16, Yekaterinburg, 620990, Russian Federation; chivpost@gmail.com 